\title{
The design of a unit sweeping gas membrane distillation: experimental study on a membrane and operating parameters
}

\author{
Mokhless Boukhriss ${ }^{1,2}$ (D) Med Bechir Ben Hmida ${ }^{3,4,5} \cdot$ Med Ali Maatoug $^{2} \cdot$ Kamel Zarzoum $^{1} \cdot \operatorname{Riadh}^{\text {Marzouki }}{ }^{6,7,8}$. \\ Habib Ben Bacha ${ }^{1,9}$
}

Received: 11 June 2019 / Accepted: 31 March 2020 / Published online: 16 April 2020

(c) The Author(s) 2020

\begin{abstract}
The paper presents the focuses of application in membrane processes for the desalination of brackish water or salt water using the sweeping gas membrane distillation (SGMD); at first, it is the least used configuration of MD, and the design of this system is arduous and very expensive, and it is used to treat solutions containing non-volatile compounds, such us salts which is totally rejected, and high purity of water was recuperated. Vapor transfer is an important thermally induced phenomenon in the membrane-by-membrane (MD) evaporation and condensation. Our SGMD distillation system was simulated using MATLAB programmers on heat and mass transfer aspects. In our research, we found that heat and mass transfer in the SGMD is determined by the evaporation temperature of the gas and the sweep rate. The operational parameter (fluid velocity) is influenced across the layer on both sides of the membrane, because it is the source of the transfer of heat and mass in many membrane processes.
\end{abstract}

Keywords Vapor transfer $\cdot$ Membrane distillation $\cdot$ Mass and heat transfer $\cdot$ Sweeping gas membrane distillation

\begin{tabular}{ll}
\multicolumn{2}{l}{ List of symbols } \\
$A$ & Area $\left(\mathrm{m}^{2}\right)$ \\
$B$ & Effective absorptivity \\
$C_{\mathrm{p}}$ & Heat capacity $(\mathrm{J} / \mathrm{kg} \mathrm{K})$ \\
$D$ & Diffusion coefficient $\left(\mathrm{m}^{2} / \mathrm{s}\right)$ \\
$F_{j}$ & Objective function $j$ \\
$H$ & Height $(\mathrm{m})$ \\
$\mathrm{HVL}$ & Heat transfer rate of phase change $\left(\mathrm{J} / \mathrm{m}^{2} \mathrm{~s}\right)$ \\
$h$ & Heat transfer coefficient $\left(\mathrm{W} / \mathrm{m}^{2} \mathrm{~K}\right)$ \\
$I$ & Intensity of solar radiation $\left(\mathrm{W} / \mathrm{m}^{2}\right)$ \\
$K$ & Thermal conductivity $(\mathrm{W} / \mathrm{m} \mathrm{K})$
\end{tabular}

Mokhless Boukhriss

mokhlessiset@yahoo.fr

1 Laboratory of Electromechanical Systems, National School of Engineers Sfax, Sfax, Tunisia

2 Higher Institute of Technological Studies of Kairouan P2, 3191 Reggada, Kairouan, Tunisia

3 Chemical Engineering Department, College of Engineering, Hail University, Hail City, Saudi Arabia

4 Physics Department, Higher School of Sciences and Technology of Hammam Sousse (ESSTHS), University of Sousse, Lamine Abassi Street, 4011 Sousse, Tunisia

5 Research Unit of Ionized Backgrounds and Reagents Studies (UEMIR), Preparatory Institute for Engineering Studies

$\begin{array}{ll}k & \text { Mass transfer coefficient }(\mathrm{m} / \mathrm{s}) \\ M & \text { Mass }(\mathrm{kg}) \\ M_{\mathrm{w}} & \text { Molecular weight of water }(\mathrm{kg} / \mathrm{kmol}) \\ m_{\mathrm{f}} & \text { Fluid flowrate }(\mathrm{kg} / \mathrm{s}) \\ m_{\mathrm{f}, \mathrm{c}} & \text { Fluid collector flowrate }(\mathrm{kg} / \mathrm{s}) \\ N & \text { Mass flux }\left(\mathrm{kmol} / \mathrm{m}^{2} \mathrm{~s}\right) \\ \text { OP } & \text { Controller output } \\ P & \text { Pressure }(\mathrm{Pa}) \\ Q & \text { Heat transfer rate }(\mathrm{J} / \mathrm{s}) \\ R & \text { Gas constant }(\mathrm{J} / \mathrm{kmol} \mathrm{K}) \\ S & \text { Collector absorber surface area }\left(\mathrm{m}^{2}\right)\end{array}$

of Monastir (IPEIM), University of Monastir, 5019 Kairouan Street, Monastir, Tunisia

6 Chemistry Department, College of Science, King Khalid University, Abha 61413, Saudi Arabia

7 Laboratory of Materials, Crystal Chemistry and Applied Thermodynamics, LR15ES01, Faculty of Sciences of Tunis, University of Tunis El Manar, 2092 Tunis, Tunisia

8 Chemistry Department, Faculty of Sciences, University of Sfax, Sfax, Tunisia

9 Head of Department of Mechanical Engineering - College of Engineering, Salman Bin Abdulaziz University, Al-Kharj, Saudi Arabia 
$S_{i} \quad$ Stream number $i$

$T \quad$ Temperature $(K)$

$D$ Thickness (m)

$e \quad$ Membrane porosity

$m$ Viscosity ( $\mathrm{kg} / \mathrm{m} \mathrm{s})$

$r \quad$ Density $\left(\mathrm{kg} / \mathrm{m}^{3}\right)$

$s \quad$ Membrane tortuosity

$s_{\mathrm{I}} \quad$ Integral time (s)

$s_{\mathrm{u}} \quad$ Ultimate period (s)

$L \quad$ Liquid

$G \quad$ Gas

C Solar collector

$T_{\mathrm{f}} \quad$ Fluid temperature (K

$T_{\mathrm{c}} \quad$ Collector temperature $(\mathrm{K})$

GM Gas in the membrane

HL Hot liquid

MD Membrane module

MEM Membrane

MET Metal

$T \quad$ Total

W Water

WA Water air

\section{Introduction}

The transfer of water vapor is a presentable phenomenon in various thermally driven membranes of processes such as membrane distillation (MD). In these processes, the driving force comes from the partial pressure difference of the water vapor through the membrane DCMD which is the most studied configurations due to salt repression. SGMD is a module that functions as an external capacitor and is required to collect permeate, which leads to additional costs that complicate the system (Lawson and Lloyd 1997; El-Bourawi et al. 2006; Curcio et al. 2010). The transfer of mass and heat, the evaporation of the membrane and the distillation of the gas-flushing membrane are essential, and the difference between the evaporation of the membrane and the MD is that the evaporation of the membrane is used for the concentration of heat-sensitive solutions (Mourgues et al. 2010; Mahmud et al. 2002,2000) compared with MD, membrane evaporation has collected much less attention in the membrane research community; the heat and mass transfer in DM intensified since the presence of DM processes (Lawson and Lloyd 1996, 1997; Alkhudhiri et al. 2012; Boukhriss et al. 2012; Schofield et al. 1987,1990; Curcio and Drioli 2005; Phattaranawik et al. 2003a; Zhang et al. 2012,2011; Qtaishat et al. 2008). Less than 6\% of MD's publications deal with SGMD (Boukhriss et al. 2012). In our study, the temperatures of the membrane module and the temperature polarization in SGMD have been explored by mathematical modeling (Boukhriss et al. 2016; Khayet et al. 2002). The model developed for the optimization of SGMD processes (Khayet et al. 2012; Khayet and Cojocaru 2013) is necessary to further explore mass and heat transfer phenomena in this technology. This study aims to provide a new understanding of mass transfer phenomena in SGMD. Here, we focus on mass transfer in SGMD, although mass transfer and simultaneous heat transfer in the evolution process of membrane techniques. This work was studied in the context of the modeling of physical phenomena (mass and heat transfer); the experimental results of our parametric study of an installation of a polytetrafluoroethylene-type membrane unit (acronym PTFE and $500 \mathrm{~L}$ ) on the pilot scale installed at the higher institutes of applied sciences and technologies of Kairouan Tunisia are presented in Fig. 1a-b.

\section{The different desalination method}

Figure 2 illustrates the desalination techniques which are classified into two broad categories: membrane processes and thermal processes. The processes acting on the chemical bonds and processes are being performed by phase change. This method's objective is to separate salt water desalination into two parts, namely fresh water containing a low concentration of dissolved salts and concentrate brine; this process is energy-consuming; for instance, various desalination techniques have been implemented over the years on the basis of the available energy (Boukhriss et al. 2012).

\section{Different configurations of MD}

The different approaches for establishing the driving force and other process requirements led to the development of various channel configurations that are widely used as classification criteria within MD technology. The most common configurations utilize a temperature difference as the driving force, while alternative approaches are considered rather exotic. Each of the MD configurations has its own advantages and disadvantages. MD technologies that establish a vapor pressure difference by temperature are as follows:

Due to its simplicity in structure, design and process operation, direct contact membrane distillation (DCMD) is the most commonly used process mode. In a DCMD process, seawater or brackish water is passed on one side of a hydrophobic porous membrane, while a colder water stream flows on the other side to directly condense the permeate water as shown in Fig. 3a. Considerable studies on DCMD have been described (Boukhriss et al. 2012; Mourgues et al. 2010; Mahmud et al. 2002).

Permeate gap membrane distillation (PGMD) is closely related to DCMD, since also in this configuration, both sides of the membrane are in direct contact with the corresponding liquid fluids and the driving force is established by means of 
Fig. 1 a Diagram of the proposed facility, b rear view (a)

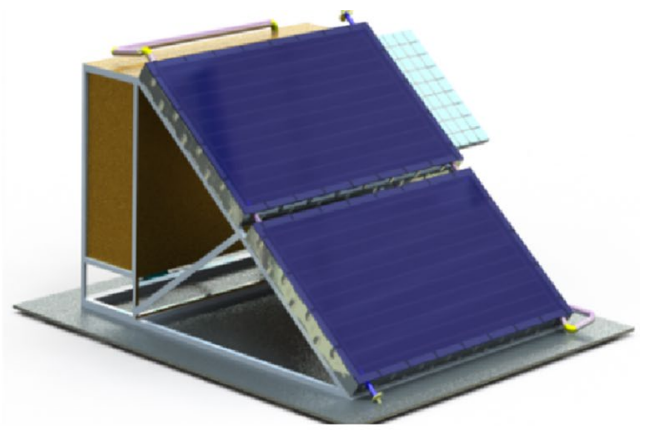

(b)

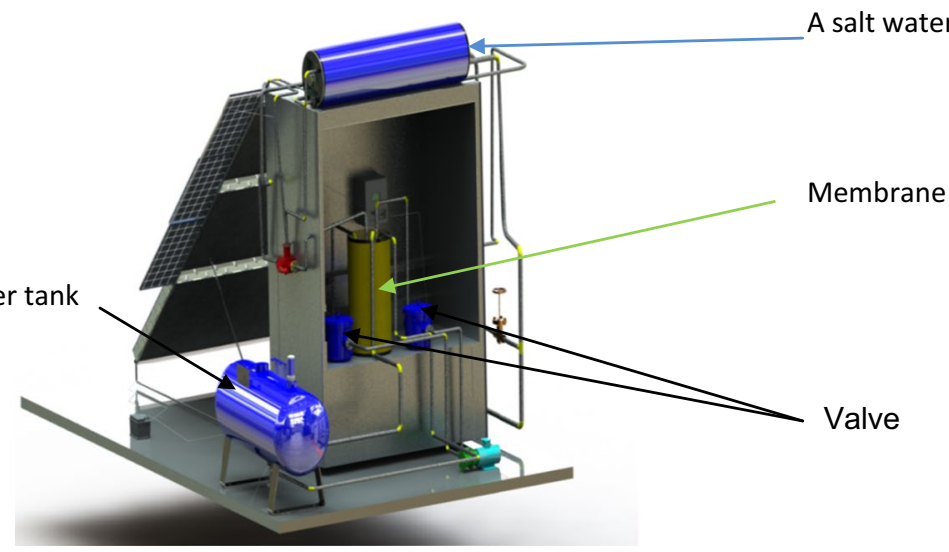

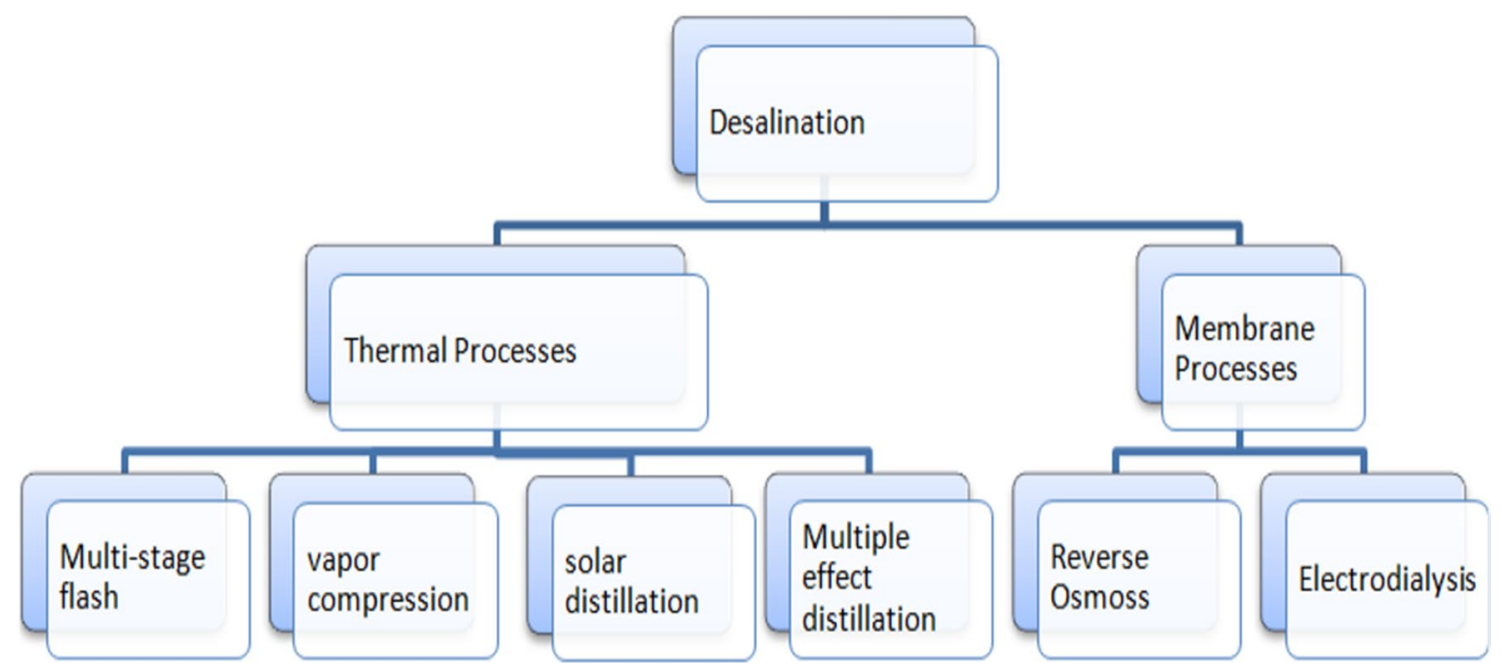

Fig. 2 Processes of desalination

a temperature difference. As shown in Fig. 3b, a third channel is introduced by an additional impermeable film that is located on the permeate side of the membrane. Since the permeate outlet is located at the highest module position, the gap between the membrane and the impermeable film fills with permeate during operation and is therefore referred to as the permeate gap (PG) or liquid gap (LG) (Mahmud et al. 2000; Schofield et al. 1987).
Air gap membrane distillation (AGMD) is shown in Fig. 3c. Related to the PGMD channel configuration, the permuate is separated from the coolant by an impermeable film next to the membrane on the permeate side. Due to a temperature difference, the volatile compounds of the feed solution evaporate at the feed side liquid-vapor interface, pass the membrane and the air gap in the gaseous phase and condense at the liquid-vapor interface on the cooled surface 
Fig. 3 MD configurations driven by a temperature difference: a DCMD, b PGMD and c AGMD (a)

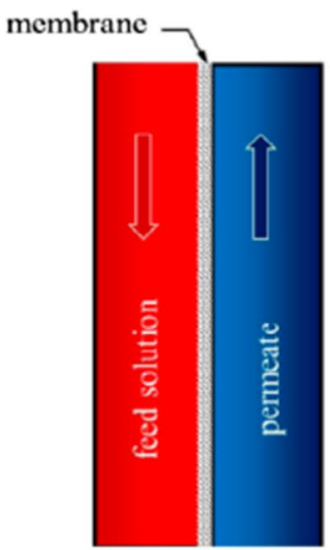

(b)

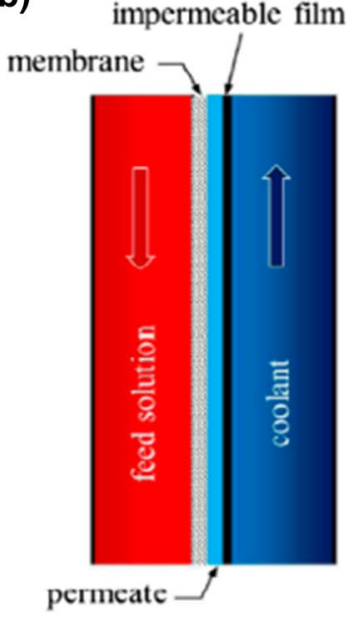

(c)

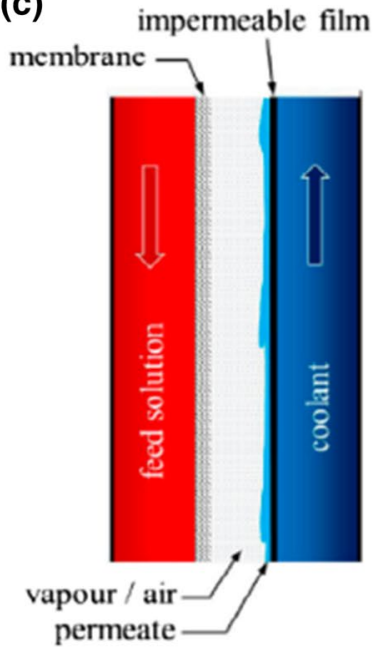

of the impermeable film (Schofield et al. 1990; Lawson and Lloyd 1996; Curcio and Drioli 2005).

Sweeping gap membrane distillation (SGMD) configuration, mentioned in Fig. 3a the vapor at the permeate side of the membrane is evacuated by a sweep gas and subsequently condensed by an external condenser. This allows for the reduction in water vapor partial pressure, thus achieving a higher driving force across the membrane Fig. 4a (Phattaranawik et al. 2003a; Zhang et al. 2011,2012).

Vacuum gap membrane distillation (VGMD) configuration, mentioned in Fig. 4b, considers a two-channel arrangement entirely related to that of SGMD. The feed solution is circulated parallel to the membrane in the evaporator channel and establishes a liquid-vapor interface at the feed side of the membrane, the flow channel on the permeate side of the membrane is designed as a dead-end channel, providing only one access point at which vacuum is tested by means of a vacuum pump, the vapor condensation and subsequent permeate extraction takes place in a condenser located outside of the module (Qtaishat et al. 2008; Basini et al. 1987; Khayet et al. 2000).

Osmotic membrane distillation (OMD) is a process that has recently appears as an attractive alternative to other concentration techniques, when high final concentration and quality are required. Osmotic distillation is illustrated in Fig. 4c.

\section{Membrane materials and modules}

The most popular micro-porous hydrophobic membranes are commercially fabricated with polypropylene (PP), polytetrafluoroethylene (PTFE), polyethylene (PE), polyvinylidene fluoride (PVDF), carbon nanotubes (CNTs) and inorganic materials, available in plate and frame, hollow fiber, tubular, spiral wound and flat sheet modules. Currently, PTFE with unique features such as high hydrophobicity and strong (a)

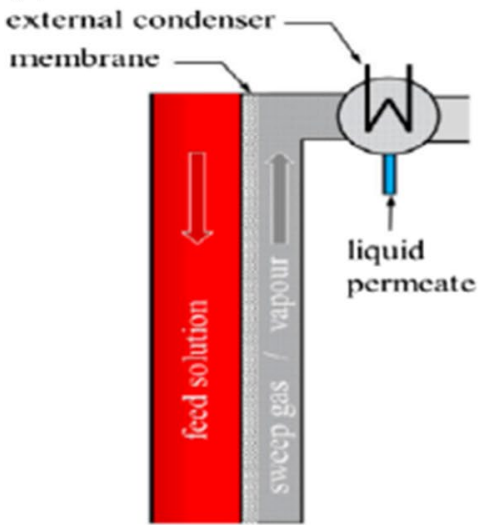

(b)

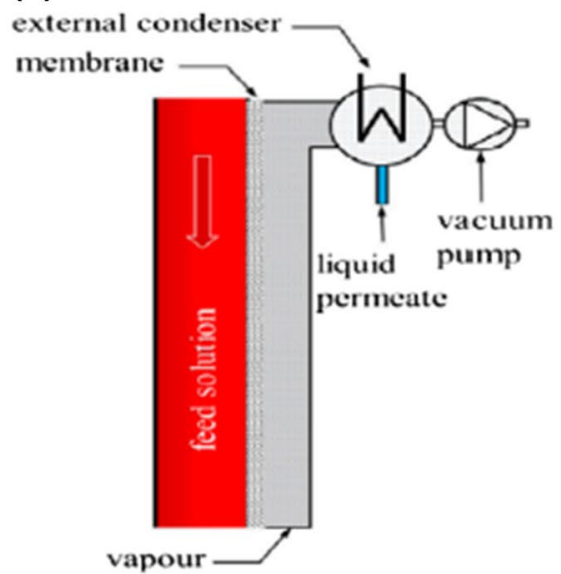

(c)

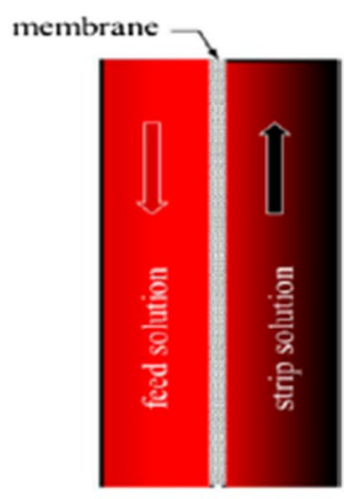

Fig. 4 MD configurations driven by approaches other than a temperature difference: a SGMD, b VMD, and $\mathbf{c}$ OMD 
resistance against severe operating conditions has dominated the commercial and laboratory applications of MD (Camacho et al. (2013); Zhang and Gray 2011; Liu et al. 2011).

\section{The membrane distillation unit}

The model for individual sweeping gap membrane distillation (SGMD) in Fig. 5 is formulated and resolved numerically on the platform, where the membrane module can be improved via a graphical interface, and the model components are linked and solved in an installation on the equations. The specifications of the components evaluated in this work are given in Table 1 and by the following equations (Alkhudhiri et al. 2012; Boukhriss et al. 2012; Schofield et al. 1990; Lawson and Lloyd 1996).

The system uses SGMD modules, for module with size specifications listed in Table 1.

The purpose is to develop a dynamic model of a SGMD module which describes the dynamic and steadystate behavior of the system. The SGMD equipment to be modeled in the membrane type is a made of polypropylene. The membrane inside the module is a hydrophobic microporous hollow fiber membrane established in a shell and tube arrangement. The hydrophobic property of the membrane allows direct contact between gas and liquid phase without dispersing one phase into the other.
Table 1 Lists of membrane parameters and solar collector

\begin{tabular}{ll}
\hline Membrane & Module \\
\hline Membrane area $\left(\mathrm{m}^{2}\right)$ & 10 \\
Thickness $(\mathrm{mm})$ & 0.14 \\
Pore diameter $(\mathrm{mm})$ & 0.2 \\
Porosity & 0.77 \\
Tortuosity & 1.9 \\
Thermal conductivity (W/m K) & 0.173 \\
Hot liquid channel thickness (mm) & 0.77 \\
Cold liquid channel thickness (mm) & 0.77 \\
Metal foil thickness (mm) & 0.98 \\
Thermal conductivity (W/m K) & 398 \\
\hline
\end{tabular}

These hollow fibers are bundled together into an array and wrapped around the center tube inside the housing. During operation, the feed solution flows over the outside (shell side), and the sweep gas (air) is applied to the inside of the hollow fiber tubes (lumen side) (Boukhriss et al. 2015; Gryta and Tomaszewska 1998). A baffle is located at the center of the bundle, the feed fluid to flow radially across the fiber array. This SGMD module was used research of Thomas (Politano and Argurio 2017) in which the feed and sweep air were made to flow counter current with respect
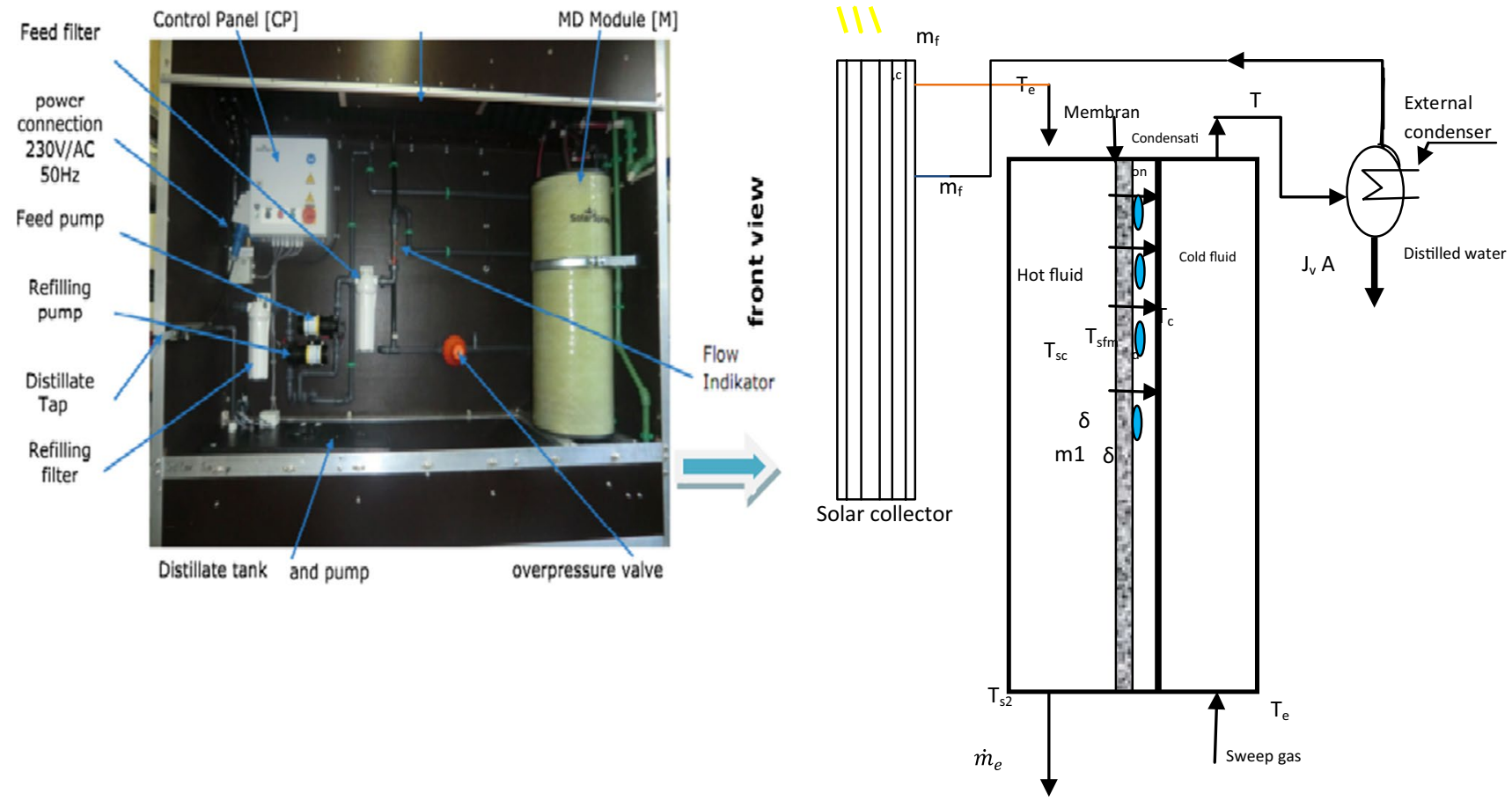

Fig. 5 Membrane distillation unit (SGMD) couples with solar collector 
to each other and tangentially to the membrane surface, and the principle of the membrane unit is shown in Fig. 6 (Liu et al. 2011).

\section{Principle of sweeping gas membrane distillation}

As explained earlier, the MD arrangement utilized in this work is SGMD; therefore, the focus lies on the working principle of this particular unit. The phenomena which take place in SGMD involve (a) evaporation of water at the hot feed side; (b) transport of water vapor through the membrane pores due to trans-membrane vapor pressure which is the driving force; (c) collection of the permeating water vapor by an inert cold sweeping gas; and (d) condensation outside of the membrane module. Usually, heat and mass transfer through the porous hydrophobic membranes are associated at the same time. Mass transfer takes place only through the pores, while heat is transferred through both the membrane matrix and its pores. Heat transfer through the membrane material is due to conduction, and heat transfer through the pores is due to latent heat accompanying the vapor flux. In addition, fluid boundary layers are adjoining both the feed and permeate side which gives rise to the phenomena called temperature polarization and concentration polarization. In Fig. 7, the temperature and concentration profile inside the SGMD is represented, the feed of sweeping gas flow in counter-current mode and tangentially to the membrane surface, the carrier gas used is air.

\section{Theoretical models}

There are two extensive theoretical approaches which permit to determine the mass and heat transfer mechanisms, temperatures and concentrations as well as the local and global permeate fluxes of a plate and frame SGMD module. Experiments were performed with this module in which hot pure water was circulated through one of the chambers and cold

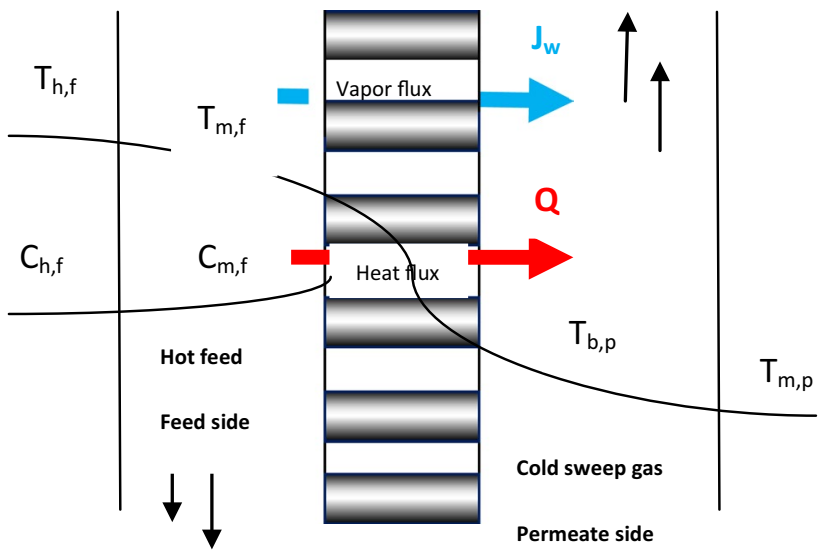

Fig. 7 Working principle of SGMD

sweeping air through the other. The cold air and hot water flow in counter current tangentially to the membrane surface.

These theoretical approaches form the basis of the modeling project in this research. The SGMD module used is a shell and tube arrangement rather than plate and frame, and a solution is used as feed rather than pure water; in this study, theoretical approaches are executed and evaluated, and also the compromise with the conducted experiments is checked, and an additional modification after evaluation is probably required due to the different types of SGMD system that is used in the differences between the two theoretical approaches that lie in the mathematical description of the vapor permeate flux. In the first model, the flux is written as a function of the transmembrane vapor pressure difference induced by the transmembrane temperature gradient. In the second model, the flux is calculated based on the feed vapor pressure and the sweeping air flowrate and air humidity. These differences will be highlighted in the following sections, and also the model simulation will be conducted for both theoretical approaches, and the results will be compared with the model that shows most accurate agreement with the stand-alone SGMD experiments which will be chosen as default. The development of a model

Fig. 6 SGMD model

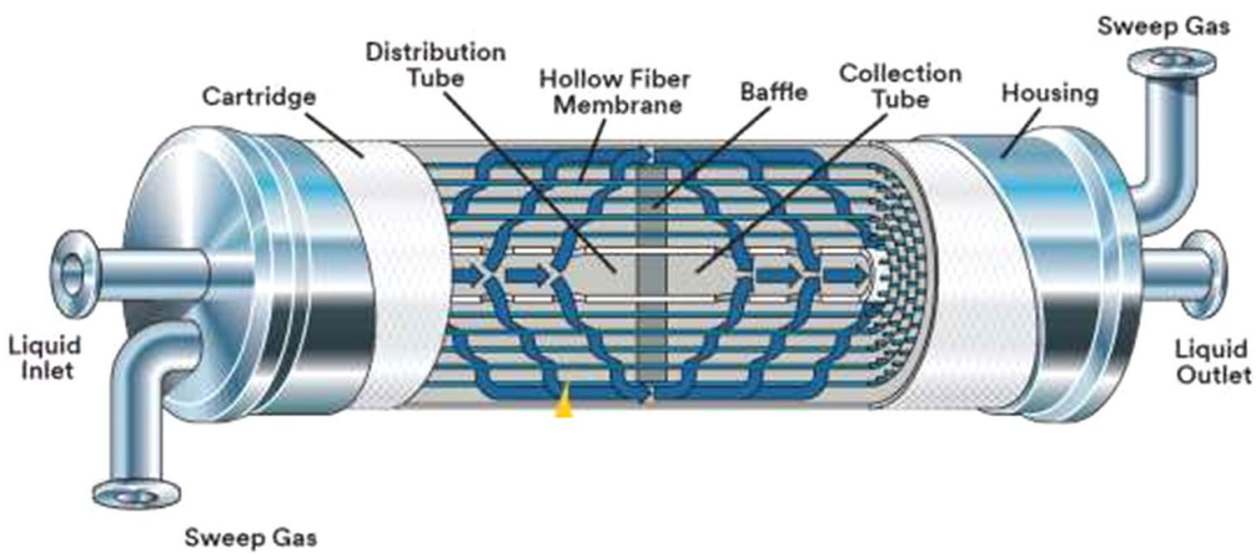


starts with the definition of boundaries for the system that has to be modeled. Usually, a boundary is placed where there are known inputs and desired outputs, and the link between the system and surroundings happens through process and environmental variables.

Three types of variables are distinguished (Mahmud et al. 2002; Schofield et al. 1987; Cussler 1997):

1. Input variables, $\mathbf{u}(\mathbf{t})$, are those which originate from the surroundings and act upon the system by crossing the system border. Influences in the system are noticeable in time after the input is imposed. A distinction can be made between manipulated and disturbance variables. The manipulated variables can be adjusted in order to keep the output variables around their preselected set points or range. Disturbances can affect the output variables but cannot be manipulated.

2. Output variables, $\mathbf{y}(\mathbf{t})$, result from the systems internal relationships and are passed via the border to the surroundings. Usually, output variables are process variables that are controlled to a preselected set point or range.

3. Internal variables, $\mathbf{z}(\mathbf{t})$, occur inside the system and are neither inputs nor outputs, but are desired characteristics. Internal variables are useful in completing the set of variables for solving the systems equations. The internal variables are linked to the inputs, and are exchanged between (sub) systems and components. Typical model inputs for given equipment include equipment dimensions, operating conditions and kinetic parameters. There are many input, output and internal variables existing to be modeled SGMD system; however, in Fig. 8, the variables which are of greatest interest are depicted. Table 2 shows a more elaborated description of these variables categorized per region.
Table 2 Control volume variables

\begin{tabular}{|c|c|}
\hline Input variables (10) & $\begin{array}{l}V_{\mathrm{f}}, T_{\mathrm{f}}, w_{\mathrm{f}}, T_{\mathrm{c}}, V_{\mathrm{a}}, T_{\mathrm{a}, \text { in }}, \omega_{\mathrm{in}}, T_{\mathrm{a}, \text { out }} \\
\quad P_{\mathrm{a}, \text { out }}, V_{\mathrm{m}}\end{array}$ \\
\hline Output variables (1) & $J_{\mathrm{w}}$ \\
\hline Internal variable (7) & $T_{\mathrm{b}, \mathrm{f}}, T_{\mathrm{m}, \mathrm{f}}, p_{\mathrm{w}, \mathrm{f}}, x_{\mathrm{m}, \mathrm{f}}, T_{\mathrm{b}, \mathrm{p}}, T_{\mathrm{m}, \mathrm{p}}, p_{\mathrm{w}, \mathrm{a}}$ \\
\hline $\begin{array}{l}\text { Feed solution } \\
\text { Input: } \\
\text { Feed volumetric flowrate, } V_{\mathrm{f}} \\
\text { Feed temperature, } T_{\mathrm{f}} \\
\text { Weight fraction solute, } w_{\mathrm{f}}\end{array}$ & $\begin{array}{l}\text { Concentrate solution } \\
\text { Input: } \\
\text { Concentrate temperature, } T_{\mathrm{c}}\end{array}$ \\
\hline Sweep gas (air) & Permeate \\
\hline Input: & $\begin{array}{l}\text { Input: } \\
\text { Air outlet temperature, } T_{\mathrm{a} \text {,out }}\end{array}$ \\
\hline $\begin{array}{l}\text { Air volumetric flowrate, } V_{\mathrm{a}} \\
\text { Air inlet temperature, } T_{\mathrm{a}, \text { in }}\end{array}$ & $\begin{array}{l}\text { Air outlet pressure, } P_{\mathrm{a}, \text { out }} \\
\text { Output: }\end{array}$ \\
\hline $\begin{array}{l}\text { Air inlet humidity ratio, } \omega_{\text {in }} \\
\text { Membrane } \\
\text { Internal: } \\
\text { Bulk feed temperature, } T_{\mathrm{b}, \mathrm{f}} \\
\text { Membrane surface feed tempera } \\
\text { Feed water vapor pressure, } p_{\mathrm{w}, \mathrm{f}} \\
\text { Membrane surface feed mole } \mathrm{f} \\
\text { Bulk permeate side temperatur } \\
\text { Membrane surface permeate si } \\
\text { Permeate side water vapor pre } \\
\text { (Solution) volume inside mem }\end{array}$ & $\begin{array}{l}T_{\mathrm{m}, \mathrm{f}} \\
\text { on, } x_{\mathrm{m}, \mathrm{f}} \\
\mathrm{b}, \mathrm{p} \\
\text { emperature, } T_{\mathrm{m}, \mathrm{p}} \\
, p_{\mathrm{w}, \mathrm{p}} \\
\mathrm{e}, V_{\mathrm{m}}\end{array}$ \\
\hline
\end{tabular}

\section{Assumptions}

Real-world physics are infinitely complex in Table 2 . In order to mathematically describe these, replacement by simplified representations are necessary. Assumptions are formulated to transform the problem from 'real' physics to simplified physical representation (Cussler 1997). The assumptions for the SGMD process are stated as (Khayet et al. 2000):
Fig. 8 The functional parameters of SGMD

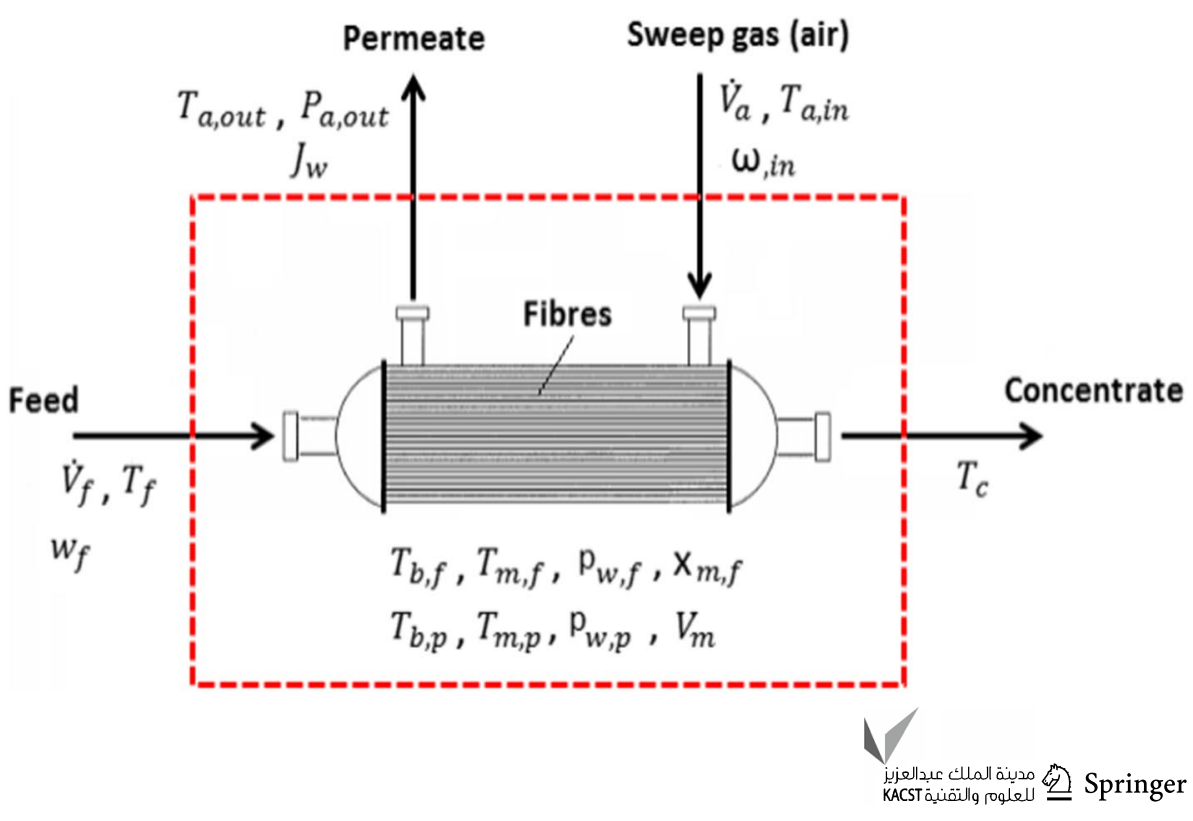


- Kinetic effects at the liquid/vapor and vapor/gas interfaces formed at both ends of the membrane pores are negligible

- Compared to a flat interface, the curvature of the interfaces is assumed to have negligible effect on the equilibrium

- The vapor and process medium phases are in equilibrium corresponding to the temperature at each side of the pores

- The feed and sweep gas are considered to flow in counter current direction.

- There is a pressure drop across the membrane.

- The humidity ratio increases along the length of the membrane.

The main assumptions used in the model are listed below:

- The flow through the distillation module has been dimensional

- The flow of permeate through the membrane is only pure water as vapor. There is no wetting event, and the salt concentration in the permuate is zero.

- Vaporization of the water takes place at the entrance of the pores of the membrane. The liquid-vapor equilibrium therefore occurs on the surface of the membrane.

- Transfer of material within the membrane is described by the diffusion model Knudsen and molecular. The viscous flow is neglected.

- Phase power

$M_{f} C_{p f} \mathrm{~d} T_{b f} \mathrm{~d} z=\dot{m}_{f} C_{p f} \mathrm{~d} T_{b f} \mathrm{~d} t-h_{f} a_{m}\left(T_{b f}-T_{m b}\right) \mathrm{d} z \mathrm{~d} t-J_{w} \Delta L_{v} \mathrm{~d} t \mathrm{~d} z$

$\frac{\partial T_{b f}}{\partial t}=\frac{\dot{m}_{f}}{M_{f}} \frac{\partial T_{b f}}{\partial z}-\frac{h_{f} a_{m}}{M_{f} C_{p f}}\left(T_{b f}-T_{m b}\right)-\frac{J_{w} \Delta L_{v}}{M_{f} C_{p f}}$

- Phase permeate

$M_{p} C_{p p} \mathrm{~d} T_{b p} \mathrm{~d} z=\dot{m}_{p} C_{p p} \mathrm{~d} T_{b p} \mathrm{~d} t+h_{p} a_{m}\left(T_{m p}-T_{b p}\right) \mathrm{d} z \mathrm{~d} t+J_{w} \Delta L_{v} \mathrm{~d} t \mathrm{~d} z$

$\frac{\partial T_{b p}}{\partial t}=\frac{\dot{m}_{p}}{M_{p}} \frac{\partial T_{b p}}{\partial z}+\frac{h_{p} a_{m}}{M_{p} C_{p p}}\left(T_{m p}-T_{b p}\right)+\frac{J_{w} \Delta L_{v}}{M_{p} C_{p p}}$

- Layer-side power limit (CLA) / membrane

$h_{f} a_{m}\left(T_{b f}-T_{m f}\right)=\frac{\lambda_{m}}{\delta_{m}} a_{m}\left(T_{m f}-T_{m p}\right)+J_{w} \Delta L_{v}$

- Boundary-layer permeate side (CLP)/membrane $\frac{\lambda_{m}}{\delta_{m}} a_{m}\left(T_{m f}-T_{m p}\right)+J_{w} \Delta L_{v}=h_{p} a_{m}\left(T_{m p}-T_{b p}\right)$

- Membrane

$d J_{w}=C_{m} \Delta p \delta_{m} \mathrm{~d} z=C_{m}\left(p_{m f}-p_{m p}\right) \delta_{m} \mathrm{~d} z$

The vapor pressure of pure water at the membrane surface can be calculated by using the Antoine equation:

$p_{i}^{0}=\exp \left(23.1964-\frac{3816.44}{T_{i}-46.13}\right)_{i=m f, m p}$

For the treatment of highly concentrated salt water, the presence of salts in the feed solution reduces the water activity and, consequently, the water vapor pressure. Thus, the partial pressure of water vapor at the surface of the membrane in the SGMD configuration is calculated by equation (Khayet et al. 2002):

$p_{i=m f, m p}=x_{w}\left(1-0.5 x_{\text {salt }}-10 x_{\text {salt }}^{2}\right) p_{i=m f, m p}^{0}$

Under these conditions, the flow can be calculated as follows (Boukhriss et al. 2015):

$J=C_{\text {global }} \cdot\left(\mathrm{PT}_{\mathrm{f}}-\mathrm{PT}_{\mathrm{p}}\right)$

where $C_{\text {global }}$ is a constant for the phenomena of mass transfer in the membrane and the boundary layer.

Figure 8 shows a mass and heat transfer element of a SGMD. In this element, the variation of the thermal energy on the hot side can be described as follows:

$C_{\mathrm{p}}, f \dot{m}_{\mathrm{f}}\left(T_{\mathrm{f}, i+1}-T_{\mathrm{f}, i}\right)=-\left(J H_{\text {latent }} \cdot D A+U\left(T_{\mathrm{f}}-T_{\mathrm{p}}\right) \cdot D A\right)$

Or. $T_{\mathrm{f}, i+1}$ and $T_{\mathrm{f}, i}$ are the discretized points of the temperatures at ieret $(i+1)$ th, $C_{\mathrm{p}}, f$ is the specific heat of food, $\mathrm{d} A$ is element of surface such that $\mathrm{d} A=W \cdot \mathrm{d} x$ ( $W$ is the width of the membrane).

The relationship between the temperature change and the flow displacement can be expressed as follows:

$$
\begin{aligned}
(\mathrm{DT}) \_= & -w\left(J_{-} i H_{\text {latent }}+U\left(T_{-}(f, i)-T_{-}(p, i)\right)\right) / \\
& \left(C_{-}(p, \dot{f}) \dot{M} \_\right) \cdot D x
\end{aligned}
$$

Consequently, the change in the supply temperature after the current has passed through each element can be described by the relation Eq. 13:

$$
\begin{aligned}
\Delta T_{\mathrm{f}, i}= & -\left(C _ { \text { global } } \left[\operatorname{EXP}\left(23.1964-3814.44 /\left(T_{\mathrm{f}, i}+227.02\right)\right)\right.\right. \\
& \left.-\operatorname{EXP}\left(23.1964-3814.44 /\left(\mathrm{T}_{\mathrm{P}, i}+227.02\right)\right)\right] H_{\text {latent }} \\
& \left.+U\left(T_{\mathrm{f}, i}-T_{\mathrm{p}, i}\right)\right) /\left(C_{-}(p, f) \dot{m}_{-} f\right) W \Delta x
\end{aligned}
$$


The supply current temperature at $(i+1)$ th can be calculated by:

$\left(T_{\mathrm{f}, i+1}=T_{\mathrm{f}, i}-\Delta T_{\mathrm{f}, i}\right)$

Likewise, the permeate temperature can be calculated by:

$$
T_{\mathrm{p}, i+1}=T_{\mathrm{p}, i}-\left(\dot{m}_{f}\right) /\left(\dot{m}_{p}\right) \Delta T_{\mathrm{f}, i}
$$

Thus, the flux at $(i+1)$ th can be calculated as:
$J_{i+1}=C_{\text {global }}\left(\operatorname{Pr}_{\mathrm{f}, i+1}-\underset{\mathrm{p}, i+1}{\operatorname{Pr}}\right)$

To solve the above equations numerically, we have developed an algorithm in Fig. 9 which allows calculating the vapor fluxes.

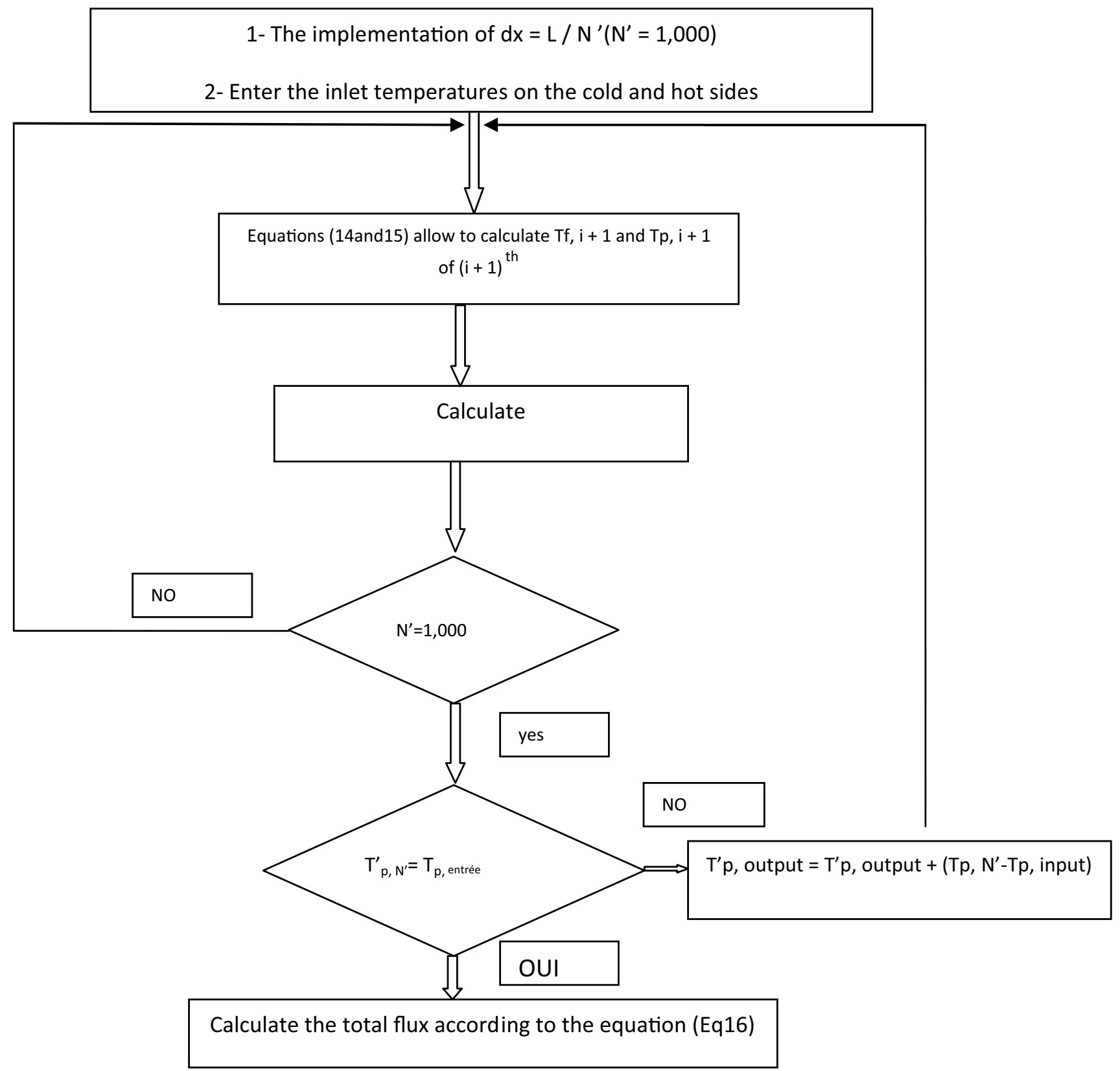

Fig. 9 An algorithm for SGMD simulation flowchart 


\section{Thermodynamic analysis of the membrane under high concentrations}

The performance of such a membrane distillation system depends on a variety of operating conditions. The optimal choice of the membrane and its characteristics are crucial to the performance of DM process. The high permeability can be obtained by increasing the porosity of the membrane, the pore size or tortuosity, while a reduction in the thickness of the membrane carefully evaluated the thermodynamic point of view.

The research presented in this section are developed in the laboratory "Thermal Desalination and Separation (TDS)" at the Fraunhofer Institute for Solar Energy Systems ISE, Freiburg, Germany.

A test system was developed for the characterization Fraunhofer ISE membranes, the study of DM different configurations and validating mathematical models.

\section{Test procedures}

The test procedures are performed with an artificial salt solution prepared with BWT Clarosal tabs $99.6 \%$ purity. The system is flushed first with $5 \mathrm{~L}$ of pure distilled water to remove undesired salt residues and clean the pipes until the measured conductivity falls below $50 \mu \mathrm{m} \mathrm{cm}^{-1}$ both side evaporator and condenser. The operating conditions are set, and the test is then introduced to an appropriate preheating period each time. The conductivity is measured on the sides of condenser and evaporator, using a conductivity meter (WTW Cond 315i) before and after the experiments. Each membrane is checked against leakage with a salt solution of $20 \mathrm{mS} \mathrm{cm} \mathrm{cm}^{-1}$ on the side of the evaporator and a solution of $30-50 \tilde{\mathrm{iS} \mathrm{cm}} \mathrm{cm}^{-1}$ on the condenser for a period of $30 \mathrm{~min}$. From the experimental point of view, the thermal efficiency can be derived from the mass flow and the energy balance in the evaporator. Thermal efficiency is given by the following relationship:

$\eta_{\mathrm{E}}=\frac{J_{\mathrm{w}} \Delta L_{v, w}}{\dot{m}_{\mathrm{f}} C_{\mathrm{pf}}\left(T_{\mathrm{f}_{2}}-T_{\mathrm{f}_{1}}\right)}$

\section{Results and discussion}

Firstly, it is necessary to mention that all the following results are based on the observed experimental conditions, under which there was neither liquid leaking into the gas side nor sweeping gas penetrating into the liquid side, namely no membrane wetting occurs due to the very low liquid side pressure (14 $\mathrm{kPa}$, one order of magnitude lower than the liquid entry pressure of a typical MD membrane).

\section{Effect of evaporation temperature on mass transfer in SGMD}

In the SGMD, the evaporation temperature of the membrane is determined under the effect of the pressure, and subsequently, it influences the mass transfer. Figure 7 shows the effect of the evaporation temperature on the vapor flow in SGMD. Equation (3) allows us to give the evolution of the evaporation temperature, which is refracted on the blue curve. Porosity of membrane $(0.1 \mu \mathrm{m})$ and a green curve for a porosity of $0.45 \mu \mathrm{m}$ were observed that if we increase the porosity, we find an increase in vapor flow; this is in agreement with the variation of speed fluid. However, the temperature at the membrane surface also increases with the evaporation rate of the temperature (Table 1), which results in an increase in the temperature of the gas. Therefore, the rate of change is not exactly the same. This difference is more evident for higher evaporation temperatures (Fig. 10). Equation (2) is used to determine the experimentally simulated relative humidity and saturation that are compared in Table 1. It can be seen that increasing the moisture content will increase vapor flow and the evaporation temperature. The saturated humidity ratio also increases as a result of the increase in gas temperature associated with the heat transfer in membrane evaporation. However, it is interesting to note that the experimentally determined humidity is much higher than the saturated humidity at all temperatures. This means that we cannot use Eq. (2) for the calculation of the outlet gas humidity because the vapor in the membrane cell might be saturated. This is further illustrated by the results in the following sections.

\section{Effect of gas flow rate on mass transfer in SGMD}

As can be seen, the sweep rate of the gas has an interesting effect on the vapor flow. This is mainly determined by the

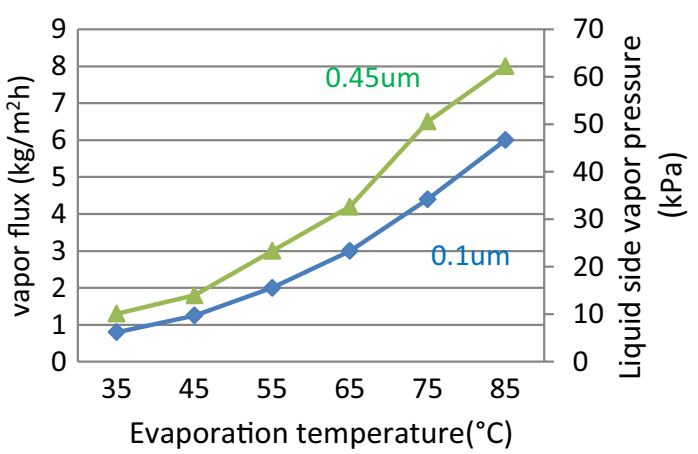

Fig. 10 Effect of evaporation temperature on vapor flux in SGMD. Constant conditions: dry nitrogen as the sweeping gas; inlet gas temperature $21{ }^{\circ} \mathrm{C}$; gas flow rate $60 \mathrm{~L} / \mathrm{h}$; liquid flow rate $20 \mathrm{~L} / \mathrm{h}$; gas side pressure 0 ; liquid side pressure $13.8 \mathrm{kPa}$ 
fact that increasing the flushing gas flow means improving the vapor retention capacity of the gas but it reduces the vapor partial pressure of the gas in the module. As the gas flow increases from 5 to $250 \mathrm{l} / \mathrm{h}$, the vapor flow increases almost linearly for PTFE membranes. At higher gas flow rates, it appears that the increase in steam flow does not become as sharp as those at lower gas flow rates, especially for the membrane at low porosities; indeed, an additional increase in flow rate gas has no significant effect on the partial pressure of water vapor. This is also expected by the effect of the boundary layer; indeed at low gas flow rates, the boundary layer is supposed to be thicker and more severe, and at higher gas flow rates, the boundary layer is minimized. Figure 11 shows that the simultaneous increase of the membrane porosity from $(0.1$ to $0.45 \mu \mathrm{m})$ and the flow of gas leads to increase in the steam flow rate.

The overall mass transfer coefficient $\mathrm{K}$ is calculated as a function of the Eq. (2), where the permeate vapor partial pressure $(\mathrm{Pp})$ at the interface of the separation layer and the purge gas is assumed to be equal to the saturation vapor pressure of the gas. The gas flow affects the vapor flow and the boundary layer (shown in Fig. 12).

The high gas flow rate can cause a thinner boundary layer which results in a reduction in the overall mass transfer resistance because this flow can affect the steam flow and temperature polarization of the membrane (Khayet et al. 2002), which always occurs at the level of the active layer. In addition, with higher gas flow rates, the transferred water vapor could be removed more quickly from the module by lowering the gas side pressure via the Bernoulli effect, which will further facilitate mass transfer through the membrane. In particular, we calculated the moisture content of gases at the exit of membrane using Eq. (2), based on the experimental vapor flow. The experimentally determined moisture ratio and the simulated saturation moisture ratio at the outlet of the flushing gas are summarized in Table 1. It can be seen that as the gas flow rate increases from 10 to $250 \mathrm{l} / \mathrm{h}$, and the temperature at the gas outlet increases slightly then

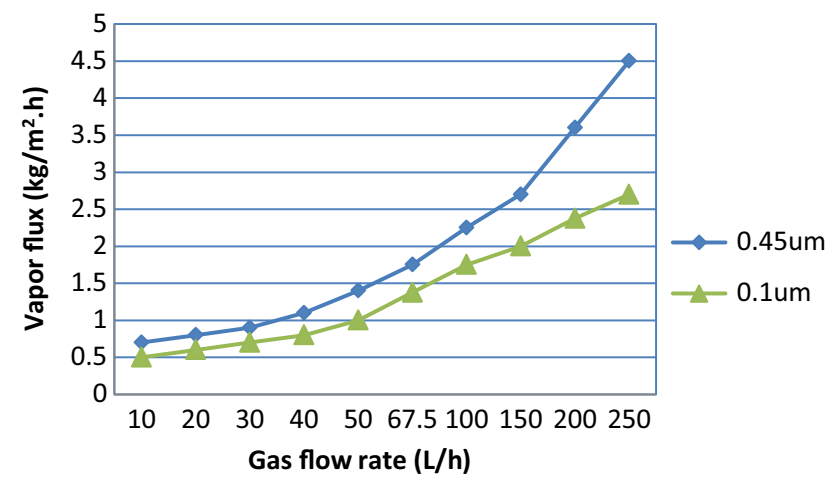

Fig. 11 Shows the effect of gas flow rate on the vapor flux in SGMD

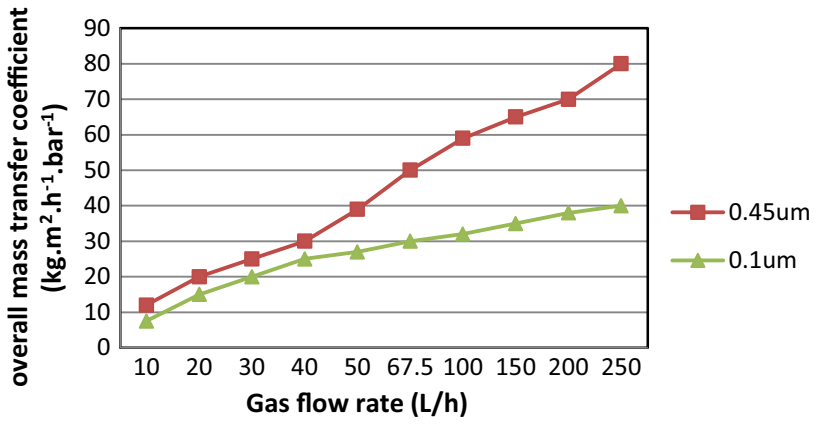

Fig. 12 Effect of gas flow rate on the overall mass transfer coefficient in SGMD. as the sweeping gas; inlet gas temperature $21^{\circ} \mathrm{C}$; evaporation temperature $45^{\circ} \mathrm{C}$; liquid flow rate $20 \mathrm{l} / \mathrm{h}$; gas side pressure 0 ; liquid side pressure $13.8 \mathrm{kPa}$

decreases slightly. The outlet temperature of the flushing gas should decrease with an increase in gas flow. However, there is more heat transferred from the gas side associated with the higher vapor flow at a higher gas flow rate. This explains that the exit temperature of the gas could increase or decrease with increasing gas flow. The saturated steam and the corresponding saturated moisture have the same tendency with the temperature of the gas as shown in Table 1. It follows that the experimentally determined moisture content decreases with an increase in gas flow.

\section{Effect of liquid flow rate on mass transfer in SGMD}

Since boundary layers could occur on both sides of a membrane, the fluid hydrodynamic conditions on both sides will affect mass transfer in SGMD. The effect of liquid flow rate on the mass transfer in SGMD is shown in Fig. 13.

It can be seen that the vapor flux increases as the liquid flow rate increases from 10 to $60 \mathrm{l} / \mathrm{h}$. This is also regarded as a result of the boundary effect. However, the favorable effect of the liquid flow rate on the mass transfer is not as

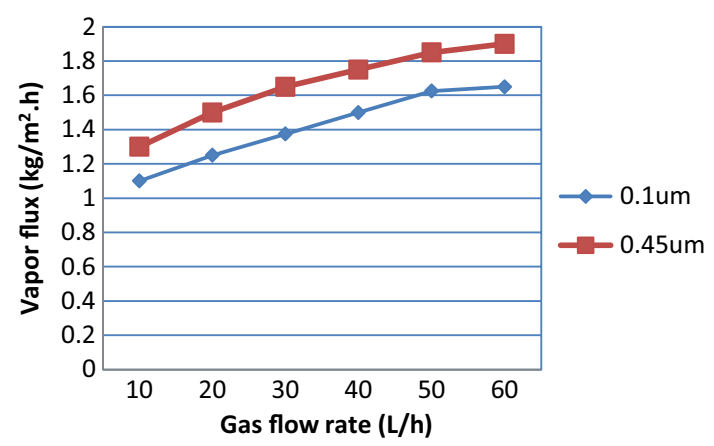

Fig. 13 Effect of liquid flow rate on vapor flux in membrane evaporation as the sweeping gas; inlet gas temperature $21^{\circ} \mathrm{C}$; evaporation temperature $45^{\circ} \mathrm{C}$; gas flow rate $60 \mathrm{~L} / \mathrm{h}$; gas side pressure 0 ; liquid side pressure $13.8 \mathrm{kPa}$

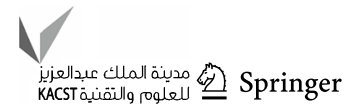


Fig. 14 SEM images of PTFE membranes
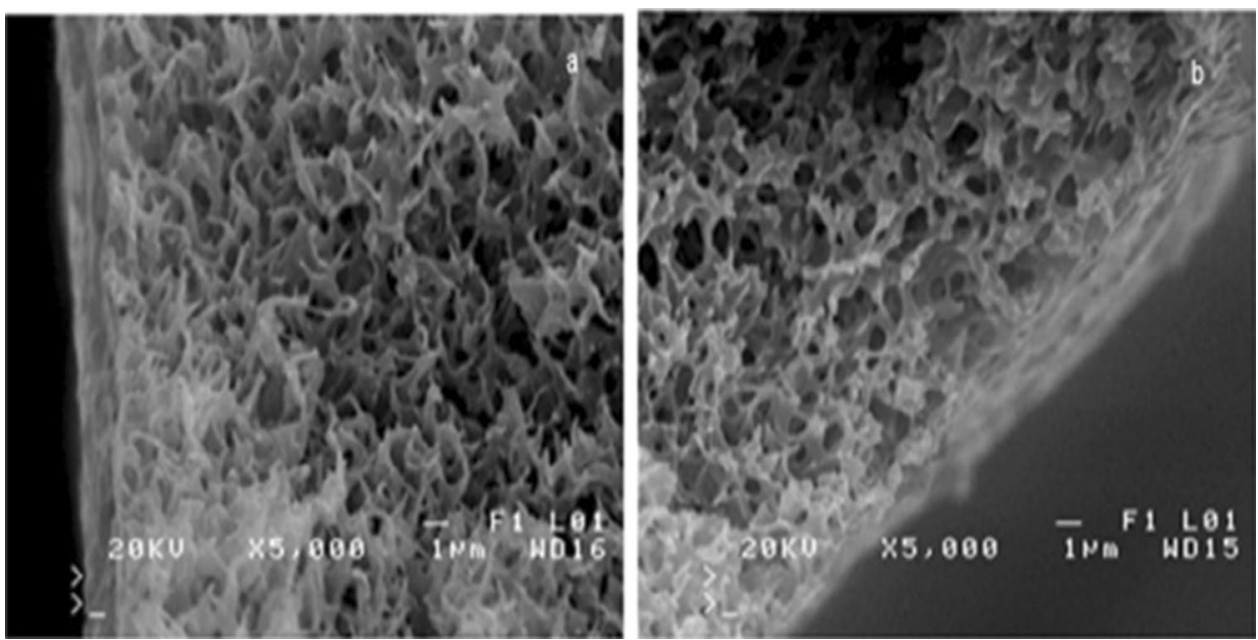

significant as that of the gas flow rate on the mass transfer shown in Fig. 8.

\section{SEM Images and Membrane Properties}

The SEM observation indicated that the PTFE membrane (according to Table 1) studied is characterized by a foam structure and is symmetrical. Some differences in pore size occurred only on the outer surface (Fig. 14a-b). The maximum pore size observed on the inner membrane surface did not exceed a few microns.

Mass transfer in the MD process is diffuse. Therefore, the permeate flux is strongly affected by the wall thickness of the membrane and the pore diameter. The results of the study confirmed that the type of membrane used has a significant influence on the efficiency of the MD process (Fig. 15).

Given the membranes having a similar wall thickness, a higher flux was obtained, having a larger pore size in a membrane. This membrane process is non-isothermal, it has two main: heat transfer mechanisms occur latent heat and heat transfer by conduction which are influenced by molecular diffusion and Knudsen in the MD process; therefore, the permeate flow increases with an increase in pore diameter.

\section{Conclusions}

The objective of this study is to develop a mathematical model for the sweeping gas membrane distillation unit and to integrate this model with an experimental study. The development of this model leads to two theoretical approaches that have been used to calculate the membrane permeate flux and the evaporation temperature. These approaches take into account the humidity in the sweep air flow, and the vapor flow to increase the amount of distilled water, so we experimentally validate the model in the SGMD. The theoretical and experimental model chords led to a sensitivity analysis of the model in the results that are compared with the SGMD literatures. We have found that an increase in the evaporation temperature from 20 to $80{ }^{\circ} \mathrm{C}$, and a gas flow rate from of
Fig. 15 Influence of feed temperature and kind of used membranes on the permeate flux and thermal efficiency feed-distilled water $T_{\mathrm{D}}=20^{\circ} \mathrm{C}$, $m_{\mathrm{F}}=m_{\mathrm{D}}=0.014 \mathrm{dm}^{3} / \mathrm{s}$
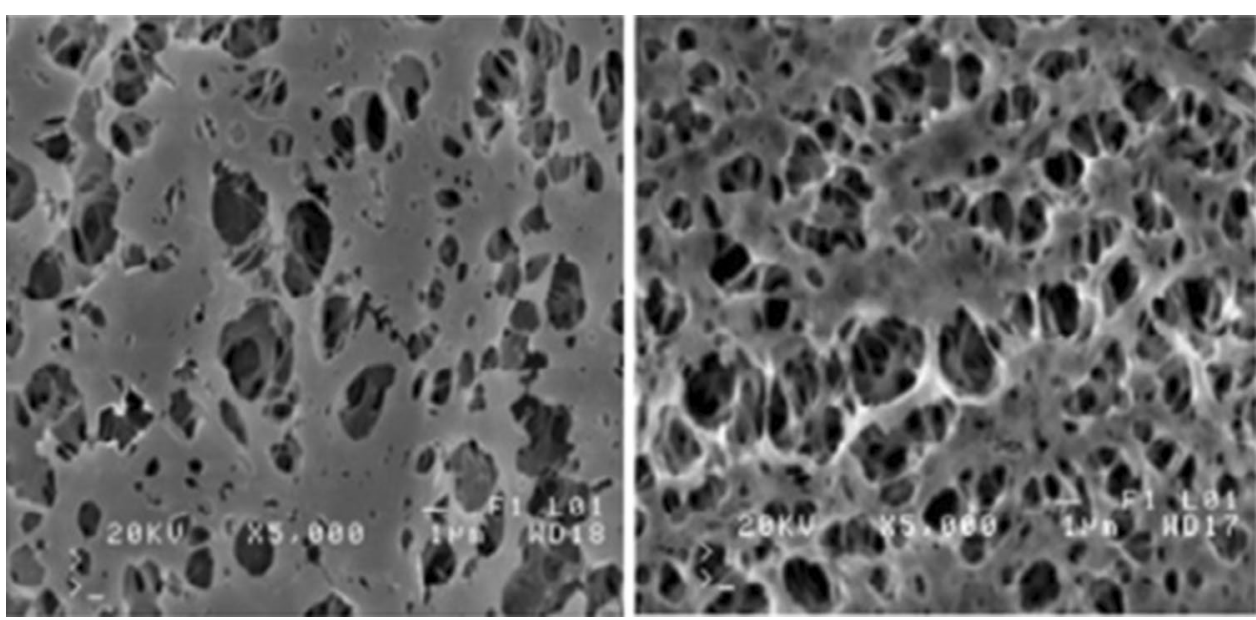
5 to $250 \mathrm{l} / \mathrm{h}$ leads to an increase in vapor flow; this analysis shows that the performance of the SGMD is consistent with the literature with a modification of some parameters, and this developed SGMD model can be used for improvements, for predictive purposes and for further research on membrane distillation processes.

Acknowledgements The investigation presented in this article was conducted as part of the development of the research project at higher institute. Higher College of Applied Sciences and Technologies of Kairouan (ISSAT KAIROUAN), University of Kairouan-Tunisia.

Author contributions All the authors participated in the definition of the techniques of the algorithms. KZ, MAM also developed the simulation software, assisted by BBH, HBB and an experimental study was made by MMB. All authors read and approved the final manuscript.

Funding Not applicable.

\section{Compliance with ethical standards}

Competing interests The authors declare that they have no competing interests.

Availability of data and materials The datasets used and analyzed during the current study are available from the corresponding author on reasonable request.

Open Access This article is licensed under a Creative Commons Attribution 4.0 International License, which permits use, sharing, adaptation, distribution and reproduction in any medium or format, as long as you give appropriate credit to the original author(s) and the source, provide a link to the Creative Commons licence, and indicate if changes were made. The images or other third party material in this article are included in the article's Creative Commons licence, unless indicated otherwise in a credit line to the material. If material is not included in the article's Creative Commons licence and your intended use is not permitted by statutory regulation or exceeds the permitted use, you will need to obtain permission directly from the copyright holder. To view a copy of this licence, visit http://creativecommons.org/licenses/by/4.0/.

\section{References}

Alkhudhiri A, Darwish N, Hilal N (2012) Membrane distillation: A comprehensive review. Desalination 287:2-18

Antonio P, Pietro A, Di Gianluca P, Vanna S, Anna C, Sudip C, Hassan AA, Efrem C (2017) Photothermal membrane distillation for seawater desalination. Adv Mater 29(2):16-35

Basini L, D’Angelo G, Gobbi M, Sarti GC, Gostoli C (1987) A desalination process through sweeping gas membrane distillation. Desalination 64:245-257

Boukhriss M, Bacha B, Zarzoum K, Zhani K (2015) Study of modeling and simulation of direct con-tact membrane distillation. Int J Sci Eng Res 6:1317-1325

Camacho LM, Dumée L, Zhang J, Li J-D, Duke M, Gomez J, Gray S (2013) Advances in membrane distillation for water desalination and purification applications. Water 5:94-196

Curcio E, Drioli E (2005) Membrane distillation and related operations-a review. Sep Purif Rev 34:35-86
Curcio E, Di Profio G, Drioli E (2010) Membrane distillation and osmotic distillation. In: Enrico D, Lidietta G (eds) Comprehensive membrane science and engineering. Elsevier, Oxford, pp 1-20

Cussler EL (1997) Diffusion: mass transfer in fluid systems, 2nd edn. Cambridge University Press, New York

El-Bourawi MS, Ding Z, Ma R, Khayet M (2006) A framework for better understanding membrane distillation separation process. J Membr Sci 285:4-29

Fang Y, Novak PJ, Hozalski RM, Cussler EL, Semmens MJ (2004) Condensation studies in gas permeable membranes. J Membr Sci 231:47-55

Gryta M, Tomaszewska M (1998) Heat transport in the membrane distillation process. J Membr Sci 144:211-222

Kast W, Hohenthanner CR (2000) Mass transfer within the gas-phase of porous media. Int J Heat Mass Transf 43:807-823

Khayet M, Cojocaru C (2013) Artificial neural network model for desalination by sweeping gas membrane distillation. Desalination 308:102-110

Khayet M, Cojocaru C, Baroudi A (2012) Modeling and optimization of sweeping gas membrane distillation. Desalination 287:159-166

Khayet M, Godino P, Mengual JI (2000) Nature of flow on sweeping gas membrane distillation. J Membr Sci 170:243-255

Khayet M, Godino MP, Mengual JI (2002) Thermal boundary layers in sweeping gas membrane distillation processes. AIChE J 48:1488-1497

Kuhn H, Forstering HD (2000) Principles of physical chemistry. Wiley, New York

Lawson KW, Lloyd DR (1996) Membrane distillation. II. Direct contact MD. J Membr Sci 120:123-133

Lawson KW, Lloyd DR (1997) Membrane distillation. J Membr Sci 124:1-25

Liu F, Hashim NA, Liu Y, Abed MM, Li K (2011) Progress in the production and modification of PVDF membranes. J. Membr. Sci 375:1-27

M. Boukhriss, R. Gharbi, K. Zhani, H. Ben Bacha, Studyof thermophysical properties of a solar desalination system using solair energy. Desalination And Water Treatment Science And Engineering, Received: 01 Mar 2012, Accepted: 18 Jul 2012

M. Boukhriss, K. Zhani, H. Ben Bacha, Optimization of membrane distillation (MD) technology for specific application desalination. Int J Adv Manuf Technol. DOI 10.1007/s00170-016-8756-4 2016.

Mahmud H, Kumar A, Narbaitz RM, Matsuura T (2000) A study of mass transfer in the membrane air-stripping process using microporous polyproplylene hollow fibers. J Membr Sci 179:29-41

Mahmud H, Kumar A, Narbaitz RM, Matsuura T (2002) Mass transport in the membrane airstripping process using microporous polypropylene hollow fibers: effect of toluene in aqueous feed. J Membr Sci 209:207-219

Mourgues A, Hengl N, Belleville MP, Paolucci Jeanjean D, Sanchez J (2010) Membrane contactor with hydrophobic metallic membranes: 1. Modeling of coupled mass and heat transfers in membrane evaporation. J Membr Sci 355:112-125

Phattaranawik J, Jiraratananon R, Fane AG (2003a) Heat transport and membrane distillation coefficients in direct contact membrane distillation. J Membr Sci 212:177-193

Phattaranawik J, Jiraratananon R, Fane AG (2003b) Effect of pore size distribution and air flux on mass transport in direct contact membrane distillation. J Membr Sci 215:75-85

Qtaishat M, Matsuura T, Kruczek B, Khayet M (2008) Heat and mass transfer analysis in direct contact membrane distillation. Desalination 219:272-292

Schofield RW, Fane AG, Fell CJD (1987) Heat and mass transfer in membrane distillation. J Membr Sci 33:299-313

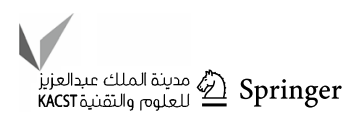


Schofield RW, Fane AG, Fell CJD (1990) Gas and vapour transport through microporous membranes II. Membrane distillation. J Membr Sci 53:173-185

Smallwood IM (1993) Solvent recovery handbook. Arnold, Paris

Zhang J, Gray S (2011) Effect of applied pressure on performance of PTFE membrane in DCMD. J Membr Sci 369:514-525

Zhang J, Li J-D, Gray S (2011) Effect of applied pressure on performance of PTFE membrane in DCMD. J Membr Sci 369:514-525
Zhang J, Gray S, Li J-D (2012) Modelling heat and mass transfers in DCMD using compressible membranes. J Membr Sci 387-388:7-16

Publisher's Note Springer Nature remains neutral with regard to jurisdictional claims in published maps and institutional affiliations. 